\title{
Determinants of Dropout Risk in Primary Education of Nepal: The Case of the Kathmandu Valley
}

\author{
Dinu Bajracharya* \\ PhD Thesis, 2018, Ochanomizu University, Tokyo, Japan
}

Even though the enrollment rate has been elevating in the primary education of Nepal, there are still numerous children who dropout from the school because of multifarious reasons that leads weighty impact for an individual and also to the society. Existing literature had already investigated key factors of dropout issues and educational intervention program after dropout in Nepal. However, determinants of school-children that cause dropout risk and instrument to measure dropout risk student has not been empirically research yet especially in the context of the Kathmandu Valley. Similarly, in-depth research regarding dropout risk student" was also not researched yet having key determinants such as: influence of school, school-teacher, and peers. Therefore, to address the gap found in the literature this study was carried out having key purpose as: to identify the key causes of dropout risk student having five major research questions as: i) Key characteristics of the dropout risk student; ii) Key issues regarding school and teachers that causes school-children to drop out risk; iii) Impact of teacher-children communication on dropout risk; (iv) Peers (inside or outside the school) that cause dropout risk ; v) Demographic status of school that cause dropout risk.

To investigate the proposed questions, this study was conducted between 2014 and 2017 at public primary schools of Kathmandu Valley (Kathmandu, Lalitpur and Bhaktapur) of Nepal. During this period (i) Questionnaire survey with school-children, (ii) Frequent semi-structured interview with school-principals and teachers, and (iii)

* Author Email: dinu.baj@gmail.com https://orcid.org/0000-0002-0008-5564 Journal homepages:

${ }^{2}$ https://www.nepjol.info/index.php/JER/index
ISSN: 2091-0118 (Print) / 2091-2560 (Online)

(C) 2019 The Author(s). http://www.kusoed.edu.np/journal/index.php/je of Education, Lalitpur, Nepal. 


\section{8 | D. Bajracharya}

FGD survey and case study on street children (dropout children) had been conducted using quantitative and qualitative research methods.

Based on the inferential statistical analysis and thematic data, students sitting at the backbench of the classroom, few/no peers, lack of conversation with teachers, and peers, not participating in school group activities, nervous while talking to teachers was found as key determinants that cause dropout risk student. Furthermore, determinants such as lack of canteen facilities, frequent exams, language barriers, learning methods, and absence of teachers also leads school-children for being at dropout risk especially for economically sound student. In addition, it became clear that peers, including school and outside of the schools, was also responsible for dropout risk who wants to be socially active. In essence, the study suggested that the relationship between schools, teachers, and friends of schools, and relations with friends outside the schools both are consequently increasing the dropout risk student.

Regarding the implications, the study fills the gap found in the literature mainly determinants for "dropout risk student" especially in Nepalese context which could be considered as the theoretical significance of the study. Also, primary school can identify suggested determinants of dropout risk student (with a detailed sub determinants) to address dropout issues after integrating an appropriate intervention programs.

Keywords: Dropout; Dropout Risk Student; Kathmandu Valley; Street Children; Teacher-student Communication

\section{Acknowledgements}

I would like to express my sincere gratitude to my advisor Prof. Dr. Hamano Takashi for his guidance, motivation, and immense knowledge-sharing. I am also sincerely and deeply grateful to the research committee members for their insightful comments and encouragement, but also for the hard questions which incented me to widen my research from various perspectives. Also, sincere gratitude to the numerous foundations for their generosity for granting me scholarships and research grants and bow my head in bottomless gratitude to my family members who became a part of my life, whether in good or bad times, and for their invaluable motivation. 